\title{
O cotidiano familiar da pessoa com esquizofrenia: cuidando no domicílio
}

\author{
The everyday family life of people with schizophrenia: caring at home
}

El cotidiano familiar de la persona con esquizofrenia: cuidando en el domicilio

Patrícia Aparecida Pedro Schülhi ${ }^{1}$, Maria Angélica Pagliarini Wadman², Catarina Aparecida Sales ${ }^{3}$

\section{RESUMO}

Estudo exploratório-descritivo de abordagem qualitativa que teve como objetivo conhecer o cotidiano do familiar quanto às suas vivências em relação ao cuidado para com o indivíduo esquizofrênico em seu domicílio. Realizado no CAPS III, em Cascavel-PR, onde foram entrevistados oito familiares, no período de maio a junho de 2009, tendo em vista a questão norteadora: "O que é isto, a esquizofrenia em seu lar?". Os depoimentos foram submetidos à análise temática de conteúdo, da qual emergiu o tema "Vivenciando a esquizofrenia no lar" e os subtemas "Sentindo necessidade de compartilhar seu pesar", "Compartilhando o preconceito" e "Sentimento de desesperança". A análise demonstrou que a vivência da esquizofrenia no lar transcende os aspectos físicos, espirituais e sociais, sobrecarregando a família. Recomenda-se a ampliação da atenção a essas pessoas no que se refere às suas necessidades de cuidado, para que juntos, doente, familiar e equipe de saúde, vislumbrem caminhos para uma assistência integral.

Descritores: Relações Familiares; Cuidados de Enfermagem; Esquizofrenia; Enfermagem Psiquiátrica.

\section{ABSTRACT}

This exploratory-descriptive study was performed using a qualitative approach with the objective of understanding the everyday family life regarding the experiences of taking care of schizophrenic individuals at home. The study was performed at the Psychosocial Care Center (CAPS III), located in Cascavel - PR, where we interviewed eight family members in the period from May to June 2009, using the following guiding question: "What does schizophrenia in your home mean?" The statements were subjected to thematic content analysis, which advanced the theme "Experiencing schizophrenia at home" and the subthemes "Feeling the need to share your burden", "Sharing the prejudice" and "Feeling hopeless". The analysis demonstrated that dealing with schizophrenia at home transcends the physical, spiritual, and social aspects, causing an overload on the family. We recommend broadening the care that is provided to these people in terms of their health care needs, so that the patient, family members and health team can, together, find the path towards comprehensive health care. Descriptors: Family Relations; Nursing Care; Schizophrenia; Psychiatric Nursing.

\section{RESUMEN}

Estudio exploratorio-descriptivo, de abordaje cualitativo, que objetivó conocer el cotidiano del familiar respecto a sus experiencias relativas al cuidado del individuo esquizofrénico en su domicilio. Realizado en el CAPS III, en Cascavel-PR, donde entrevistamos ocho familiares entre marzo y junio 2009, mediante la pregunta orientadora: "¿Qué es esto, la esquizofrenia en su hogar?" Los testimonios fueron sometidos a análisis temático de contenido, emergiendo el tema "Experimentando la esquizofrenia en el hogar" y los subtemas "Sintiendo necesidad de compartir su pesar", "Compartiendo el prejuicio" y "Sentimiento de desesperanza". El análisis demostró que la experiencia de la esquizofrenia en el hogar trasciende aspectos físicos, espirituales y sociales, sobrecargando a la familia. Recomendamos la ampliación de la atención de dichas personas en lo referente a sus necesidades de cuidado, para que juntos, enfermo, familiar y equipo de salud, vislumbren caminos para una atención integral.

Descriptores: Relaciones Familiares; Atención de Enfermería; Esquizofrenia; Enfermería Psiquiátrica.

\footnotetext{
1 Enfermeira, Mestre em Enfermagem. Maringá, PR, Brasil. E-mail: patyschulli@hotmail.com.

2 Enfermeira, Doutora em Filosofia da Enfermagem, Professor, Universidade Estadual de Maringá (UEM). Maringá, PR, Brasil. E-mail: angelicawadman@hotmail.com.

33nfermeira, Doutora em Filosofia da Enfermagem, Professor, UEM. Maringá, PR, Brasil. E-mail: casales@uem.br.
} 


\section{INTRODUÇÃO}

A reforma psiquiátrica no Brasil tem como uma das vertentes principais a desinstitucionalização, com a consequente desconstrução do manicômio e dos paradigmas que o sustentam. Esta transição trouxe consequências importantes para a família, o doente e os profissionais de saúde. Devemos ressaltar ainda que, de acordo com estas mudanças, que têm como foco manter a pessoa com transtorno mental em seu contexto familiar e social, o profissional da saúde deve voltar-se para a prática exigida por essa clientela, que envolve o cuidado no seu sentido mais amplo, ou seja, ser executado de acordo com a necessidade estabelecida por eles, e não como a determinada pela equipe de saúde ${ }^{(1)}$.

Neste sentido, o estabelecimento de um liame pode fortalecer uma relação de confiança entre a equipe, o usuário e a família, propiciando uma convivência que deve ser sincera e de responsabilidade. Sendo assim, a formação de vínculos vai facilitar a parceria, pois pelo relacionamento haverá uma ligação mais humana, mais singular, com a busca de um atendimento que melhor se aproxime das necessidades dos usuários e famílias, implementando a atuação da equipe mais sensível à escuta, à compreensão de pontos de vulnerabilidade e à construção de intervenções terapêuticas individuais ${ }^{(2)}$.

O desgaste da família ao cuidar de uma pessoa com esquizofrenia deriva, em parte, do fato de que muitas vezes, apesar de preconizar a implantação de uma rede de serviços de saúde mental na comunidade, essa rede não consegue atingir essas famílias, as quais, nestes casos, sentem-se isoladas quando não estão inseridas em um serviço adequado que thes ofereça acolhimento(3), e também, por não estarem preparadas para conviver com a sobrecarga que o transtorno mental acarreta na família, pelos sintomas da doença.

Estudo realizado ${ }^{(1)}$ com familiares que convivem com a esquizofrenia em seu lar, demonstra a necessidade da utilização de um processo de cuidar em que as mesmas não sejam apenas pessoas esquecidas em suas vicissitudes, mas sejam acompanhadas nesse processo, que estabeleçam metas e troquem experiências com a equipe, para assim viver de forma menos dolorosa com a esquizofrenia. Nestes momentos, é importante que os serviços de apoio estejam preparados para acolher e escutar as necessidades da família, fornecendo o suporte necessário para que ela consiga alcançar a reestruturação(4).

Desta forma, a conduta não deve estar voltada somente para acolher o sofrimento, mas também para outros procedimentos que venham a contribuir para a adesão da família ao serviço, pois, além de atender o usuário, é preciso fortalecer seus vínculos com os familiares ${ }^{(5)}$.

Atualmente a Enfermagem tem interesse maior em compreender a experiência dos familiares no convívio com as pessoas com transtorno mental, em conhecer suas dificuldades cotidianas, suas percepções em relação aos serviços de saúde mental, e, principalmente, em demonstrar suas necessidades nesse processo. Diante disto, este artigo teve como objetivo conhecer o cotidiano do familiar quanto às suas vivências em relação ao cuidado à pessoa esquizofrênica em seu domicílio.

\section{PERCURSO METODOLÓGICO}

Pesquisa descritiva e exploratória de abordagem qualitativa, por permitir ao pesquisador familiaridade com o ambiente, fato ou fenômeno, clarificando conceitos e conhecer tudo o que pode ser percebido pelos sentidos ou pela consciência, de modo a permitir sua interpretação e descrição(6-7).

O estudo foi realizado no Centro de Atenção Psicossocial - CAPS III, situado no município de CascavelPR no período maio a junho de 2009. Foram entrevistados oito familiares de pacientes egressos de hospitais psiquiátricos com diagnóstico de esquizofrenia (F20 da CID-10) que estavam sendo tratados e acompanhados na instituição, desde 2006, ano de início do atendimento pelo serviço. Os critérios de inclusão foram: ser família da pessoa com esquizofrenia atendida no CAPS III no período de coleta de dados e morar na região urbana do município de Cascavel, o critério de exclusão foi a pessoa com esquizofrenia e seus familiares serem menores de 18 anos. Esclarecemos que inicialmente, foram encontrados 14 familiares que se adequavam aos critérios do estudo, porém dois se recusaram a participar e quatro deles não foram encontrados no endereço, sendo assim, o estudo constituiu-se de oito familiares. Todos os participantes assinaram o Termo de Consentimento Livre e Esclarecido.

Os depoimentos foram obtidos mediante entrevista gravada. Para iniciá-la, os depoentes foram inquiridos 
com a seguinte questão norteadora: "O que é isto, esquizofrenia em seu lar?"

Utilizamos a técnica de análise de conteúdo categorial, definida como um conjunto de técnicas de análise das comunicações que utiliza procedimentos sistemáticos e objetivos de descrição do conteúdo das mensagens ${ }^{(8)}$. Esta técnica permite ao pesquisador conhecer as palavras e suas significações. É uma busca por outras realidades por meio das mensagens. Assim sendo, os relatos foram transcritos integralmente, de forma a proceder às três fases que constituem a análise de conteúdo: pré-análise, exploração do material e inferência e interpretação(8).

Рага o estudo, foram considerados os preceitos éticos referentes a pesquisas que envolvem seres humanos estabelecidos pela Resolução 196/96 do Conselho Nacional de Saúde, e a pesquisa foi avaliada pelo Comitê Permanente de Ética em Pesquisa Envolvendo Seres Humanos da Universidade Estadual de Maringá e por ele aprovado mediante o Parecer N. 113/2009. Рara manter o anonimato, os sujeitos foram identificados com nome de pássaros.

\section{RESULTADOS}

Após a análise dos depoimentos, utilizando do método proposto, emergiu o tema "Vivenciando a esquizofrenia no lar", que deu origem aos subtemas "Sentindo necessidade de compartilhar seu pesar", "Compartilhando o preconceito" e "Sentimento de desesperança".

\section{"Vivenciando a esquizofrenia no lar"}

\section{Sentindo necessidade de compartilhar seu pesar}

O viver do ser humano caracteriza-se por elo constante em estar próximo a outras pessoas que fazem parte de seu cotidiano. Assim, relacionar-se com os outros faz parte de nosso existir, tornando-nos capazes de tocar e nos deixar tocar por outros e, sendo basicamente nessa situação que se torna possível receber e fazer manifestações de solicitude. Por exemplo, em sua linguagem, Beija-flor transmite que em seu cotidiano como cuidadora de um familiar esquizofrênico, além de conviver com a sobrecarga de sua missão, também sofre com as atitudes de descuidado de seus familiares. O relato abaixo nos dá concepção primária do que é conviver com esta falta de apoio.

A minha família já fala: "Não, essa menina aí é muito folgada". Eles entendem o meu lado, mas eles não entendem o lado dela. Eles não estão sabendo direito o que está acontecendo com ela. Ela tem problema e eles não aceitam ela, a doença dela. Eles querem aceitar ela só trabalhando, e ela não tem condições agora. Está difícil, não é fácil. Ai... eu nem quero falar[...]. Às vezes a gente pede para a familia, meus filhos, eles reconhecem. Às vezes, quando eles podem, eles me ajudam. Às vezes eu não gosto nem de lembrar. É que eu já passei muito na minha vida, sabe? Desde que eu caí doente, eu era uma mulher assim... que eu tinha tudo para viver feliz. Eu sou uma pessoa feliz, mas tem parte que não dá para ser feliz, sozinha assim, sem ter pessoas (Beija-flor)

$\mathrm{Na}$ linguagem de Beija-flor apreendemos que o estresse por cuidar de um familiar esquizofrênico pode exacerbar quaisquer problemas psicológicos, sociais ou financeiros que a família possa estar vivenciando. Relativo à questão, um estudo enfoca que para amenizar a sobrecarga da família de uma pessoa esquizofrênica, é essencial a inclusão da mesma na atenção psicossocial, e o processo de reabilitação psicossocial e desinstitucionalização só serão efetivos com a participação da mesma ${ }^{(4)}$.

Atentando-nos ainda para a fala da depoente, observamos que, no convívio com a esquizofrenia, as relações interpessoais e a comunicação entre seus membros geralmente ficam prejudicadas e a doença surge como um mal-estar, causando sofrimento e desajuste nas relações; percebe-se que as famílias demonstram dificuldades em lidar com a pessoa com transtorno mental ${ }^{(9)}$. Neste pensar, notamos que no final da unidade a depoente transmite sua agonia demonstrando sentimentos de desesperança e tristeza que a fazem sentir-se abandonada.

Nem meu marido não dava muito apoio, porque ele achava que era loucura dele, que eu tinha que largar ou tinha que deixar ele quebrar tudo dentro de casa, e eu nunca deixei, nunca deixei. Porque eles aqui jogam os problemas tudo por cima de mim: se ele tem que ir para o PAC, se ele tem que ir para o hospital, você acha que pai e irmão vão acompanhando? Eu posso ou não, sou eu. Eu tenho que ir. 
Pergunte para ele se algum dia o pai pousou com ele no PAC. Nunca! (Mandarim)

Acerca dos sentimentos expressos por Mandarim, constatamos que a sobrecarga do cuidado, a falta de apoio de outros familiares e o comportamento do doente fazem-na sentir-se exausta, sem forças para prosseguir em seu caminho, mas mesmo assim ela permanece ao lado de seu filho. Ao assumir o cuidado do filho, Mandarim, busca sentido para ter se tornado cuidadora. Recorre ao laço consanguíneo de mãe para explicar sua condição, que ela recebe como uma missão, uma incumbência divina, tarefa que the foi confiada ${ }^{(1)}$.

Nesta sub-temática, distinguimos implicitamente o desejo do cuidador familiar em compartilhar o fardo que traz sobre seus ombros, pois a sobrecarga é um fator que influencia o manejo do paciente com transtorno mental e a qualidade de vida do cuidador ${ }^{(10)}$.

\section{Compartilhando o preconceito}

Um dia eu fui retirar um dente lá no centro, cheguei lá e falei que era para tirar o dente do meu filho e o dentista falou assim que não iria tirar o dente de gente louca, porque ele (filho) ia entrar lá e quebrar todos os aparelhos dele, tudo. Naquele dia eu chorei o dia inteiro. Ai, meu Deus, parece que é com você, não é? É uma tristeza, parece que até que eu falei assim: "É porque ele não tem um filho igual ao meu", porque se tivesse ele não tinha falado aquilo. Todo mundo critica, é um louco, é um doido, não vale nada - é assim que o povo fala. o povo que não entende, sabe, o problema da doença, porque até de louco o meu filho foi chamado.. (Carolina)

A atual política brasileira de saúde mental baseia-se nos referenciais basaglianos, que indicam o retorno e a permanência da pessoa com transtorno mental a seu meio social, o que significa próximo à família e à comunidade $^{(11)}$. Todavia, este enfoque de socialização parece ser uma realidade distante no cotidiano de Carolina, uma vez que esta exprime em sua fala seu pesar ao sentir que seu ente querido ainda sofre preconceitos pelo estigma da doença. Manifestando sua tristeza pelo descaso do profissional em não considerar seu filho como um ser humano, mas apenas como um "louco". O profissional considerou apenas a percepção do mundo, negligenciando compreender não apenas a situação do doente, mas principalmente a condição do familiar.

Algumas vezes, o preconceito atua de tal forma que o transtorno mental torna-se sinônimo de perigo iminente. O afastamento segue como um dos principais sintomas do preconceito, conforme relata a depoente.

Os vizinhos mesmo têm medo, os vizinhos faziam tirar mesmo, de verdade, de não vir aqui, de tirar as meninas, as coleguinhas das minhas filhas, não deixarem vir aqui. (João-de-barro)

A expectativa de que este preconceito se transforme em compreensão é algo de que os familiares têm esperança. A incompreensão aqui relatada se traduz pela falta de diálogo. Neste sentido, o transtorno mental aparece circunscrito a um espaço que há muito tempo foi utilizado para destituir o indivíduo de sua convivência com a família e a sociedade. Em sua mensagem, João-debarro demonstrou sentir que as pessoas ao seu redor vêm à pessoa a partir da forma como ela se apresenta, sem considerar suas vivências, experiências e, principalmente, o que elas trazem no seu interior, no seu âmago.

Por mais que os outros falem "Ah, está carregando ela aí, fica andando com filha grandona para cima e para baixo", mas eles não sabem o problema que eu estou carregando. Então eu acho assim que o dia que eles descobrirem o que é que eu estou fazendo, aí eles vão dar valor, eles vão falar: "Nossa, ela tem razão". Então, isso aí na cabeça do povo tem. Eu acho que isso ai é falta de fazer pergunta, de diálogo, preconceito. Chamavam ela de louca no colégio, agrediam ela, falavam "Nossa, essa menina é louca, tem que internar no São Marcos". Eu falava: "Não, vocês têm que entender que ela é doente, ela tem o problema dela e ela é boa, é uma menina boa, ela não é ruim" (Beija-flor)

A rotulação a que o indivíduo é submetido aumenta ainda mais o processo de estigmatização e provoca o afastamento de pessoas que outrora fizeram parte de seu convívio social. Rotular o indivíduo esquizofrênico de louco-drogado-vagabundo é a maneira encontrada pelas pessoas da comunidade para entender o que está acontecendo, no entanto o sofrimento das pessoas que tem um de seus membros com transtorno mental é muito grande, estudo realizado com familiares expressa 
que, apesar deles relatarem que estão levando a vida normalmente, demonstra em sua expressão corporal e facial o sofrimento, ou seja, uma sobrecarga emocional pela condição por eles assumida pelos longos anos de cuidado(12). Sobre este pensamento da comunidade, destacamos a fala a seguir:

Ele é filho de uma amiga minha. Um dia ele chegou aqui, veio trazer um convite de chá da irmã dele, que estava esperando nenê, e ele falou assim: "Cadê o maconheiro? Ele está aî?". Eu dei risada, fiquei até sem graça, falei "Nossa, olha o que o piá foi falar!" Nossa, minhas amigas sempre procuraram me ajudar, só que tinham medo de vir aqui. E a gente está assim, menina, de um jeito que, é difícil quem vem aqui. Difícil, nossa! o povo se retira, se retira tudo! (Coruja)

Desde a Antiguidade, a pessoa com transtorno mental ora vive momentos de glória, ora de estigmatização, dependendo da sua concepção social. Por exemplo, na Antiguidade e na Idade Média os denominados "loucos" eram classificados como poderosos, divinos, e em períodos posteriores, como perigosos e uma ameaça à sociedade ${ }^{(13)}$. Assim sendo, o estigma e o preconceito em relação à pessoa com transtorno mental constituem um aspecto que o marca durante toda a sua trajetória e toda a sua história. Muitos dos pensamentos e o imaginário sobre a pessoa com transtorno mental são construídos a partir do que se passa de uma geração para outra, justificando-se, assim, o pensamento de que é perigoso, precisa ser excluído da sociedade, entre outros. Nesse pensar, notamos no discurso de Coruja que o falatório das pessoas transforma seu dia a dia em um grande pesar pelo que exprimem sobre seu filho.

As pessoas de fora dizem: "Ele é um vagabundo, "porque seu filho não presta", porque ele é isso, porque ele é aquilo. Não, não é assim. Eu briguei com meio mundo já por isso: porque eu não admito chamarem ele de vagabundo e nem xingar ele porque ele nunca pediu para ninguém, nunca. Se falar para mim "seu filho é um bêbado, um louco", ah, eu já corto. Quando a gente mudou para cá falaram assim que estava mudando uma turma de maconheiros, disseram que era uma turma da pesada. (Mandarim)
Durante nossas leituras, depreendemos que outro aspecto evidenciado é a não aceitação, por parte do familiar, deste tipo de comportamento da sociedade. Sua revolta parece ocorrer, principalmente, pela falta de entendimento em relação à patologia. Mais uma vez os aspectos históricos se fazem presentes, arraigados no transtorno mental. Na narração de Mandarim, apesar de expressar ao mundo o carinho que tem por seu filho e a importância de ele ser compreendido pela comunidade, entendemos que ela experiencia um viver ambíguo, pois, se por um lado seu filho faz parte de sua existência, por outro lado, desperta em outras pessoas manifestação de discriminação.

Para mim foi muito doído, sabe? Foi mais doído do que se fosse em mim. Teve muita gente que mandou eu atropelar ele de casa, que eu estava sofrendo com uma pessoa que não tinha nada a ver comigo. Eu senti muita gente indiferente, se afastou, olhava, sabe, com nojo, com desfeita para ele, e isso me machucava muito. (Águia)

O processo de gestação desenvolve na mãe o sentimento de que o filho é parte de seu próprio corpo, isto é, faz parte de si mesma e está desde sempre inserido em sua existência. Na fala de Águia, notamos seu pesar ante a fatalidade do filho que ela moldou em seu ventre. Quanto à esta questão, mencionamos que as grandes tristezas são mudas, e quando o outro com quem mantemos comunhão afetiva não se encontra no mesmo patamar de sentimentos, acabamos por nos retrair em nós mesmos, principalmente em se tratando de sentimentos morais, sociais, estéticos e religiosos ${ }^{(14)}$.

Eu tinha vergonha de contar para as pessoas que eu tinha um filho com problema em casa, eu não contava para ninguém o problema dele, eu escondia para mim, aquilo estava me matando, me sufocando. Comecei a me abrir ali no posto de saúde. Eu falava assim: "Meu Deus, por que o pessoal vai se afastar da minha casa?" Muita gente se afastou. Não tem nada a ver, eu sempre falei que essa doença não é contagiosa. Se você conversar com dez pessoas, umas cinco falam "manda embora, é um vadio". A própria mãe falou para o meu marido, no telefone. Quando ele me contou isso eu chorei, eu falei "não, você não falou com a mãe dele". "Claro que falei". Falei "não, a mãe dele sou eu". (Águia) 
A preocupação com os outros é uma constante na vida destes familiares, e o fato de não comentarem sobre a presença de um filho esquizofrênico nos leva a crer que esta atitude é concretizada em forma de proteção e amparo. O preconceito alheio passou a ter um significado nos próprios sentimentos do familiar, porque para protegê-lo era necessário manter o segredo, o silêncio. Ao dizer "eu sempre falei que essa doença não é contagiosa", a depoente traz em suas palavras um misto de seus próprios sentimentos, que se desvelaram em sua trajetória com seu familiar adoecido; ou seja, sua história por si só a fez perceber o lado positivo e negativo de cuidar de um indivíduo esquizofrênico.

O afastamento segue como um dos principais sintomas do preconceito, conforme a depoente declara. Não significa uma forma de descuido, de vergonha ou da família esconder a pessoa com transtorno mental, mas um jeito de cuidar sem expor seu familiar a zombarias e maus tratos ${ }^{(1)}$. O preconceito e a estigmatização podem estar relacionados tanto ao comportamento da pessoa derivados dos sintomas da doença, quanto ao sentimento relacionados às experiências, as quais derivam a culpa, raiva, angústia, e tantas outras que podem surgir por causa da presença do transtorno mental na família e da solidão ao cuidar, vivenciada pelo cuidador ${ }^{(12)}$.

Apreendemos que as emoções estão sujeitas à disciplina social, o comportamento é dado conforme os acontecimentos e as circunstâncias e a sociedade estabelece o modo como devemos agir. Sentimentos como o amor, ódio, alegria, dor, temor e cólera se apresentam sob a forma de reações coletivas, e é no grupo do qual fazemos parte que aprendemos a exprimir e sentir estas emoções ${ }^{(13)}$.

\section{Vivenciando sentimento de desesperança}

Nesta subcategoria, a desesperança é um sentimento que se manifesta com frequência e as vicissitudes às quais estes familiares estão submetidos permeiam seu cotidiano de forma a alterar os padrões de cuidado até então prestados pelas famílias. Neste sentido, o cuidado passa a estar atrelado ao sofrimento, surgindo a sensação de que, aos poucos, a esperança se esvai.
Ah, é muito triste, nossa! A gente cansa de ficar lidando assim, e saber que não tem cura, a doença. O que eu fazia era só chorar, não tinha outra coisa para fazer. Eu sentia uma tristeza grande eu dizia: “Ai, meu Deus, será que é só comigo que está acontecendo isso? Será que os outros também têm problemas que nem eu?" Eu pensava assim. Só Deus que eu peço numa hora dessas. Eu acho que tem mais gente sofrendo, quando eu tô sofrendo tem outro que tem um problema pior do que eu, sabia? Tem gente que não tem braço nem perna para andar. (Carolina)

A compreensão é um sentimento que desenvolve no ser humano a força necessária para emergir de sua angústia e vislumbrar novas possibilidades quando vivencia alguma vicissitude em sua vida. Assim, observamos na linguagem de Carolina que a mesma angústia que a faz quedar perante o mundo aviva-lhe $o$ entendimento de sua situação, e ao dizer "eu acho que tem mais gente sofrendo, quando eu tô sofrendo tem outro que tem um problema pior do que eu [...]. tem gente que não tem braço nem perna para andar", ela demonstra ter consciência de que existem no mundo pessoas que apresentam problemas de saúde mais complicados e graves do que o seu, e essa constatação a faz sentir-se conformada em cumprir sua missão, mesmo sentindo-se sobrecarregada.

Um estudo relativo à questão demonstra que, mesmo sentindo-se sobrecarregados, os familiares também sentiam satisfação em cuidar do paciente. Uma possível explicação é que a companhia proporcionada representa um ponto positivo no relacionamento familiar, contribuindo para que o cuidador sinta satisfação por cuidar do paciente, apesar de ter que realizar muitas tarefas ao fazê-lo(15).

A nosso ver, estas dificuldades podem ser experienciadas pelo cuidador de modo mais ameno quando a presença dos profissionais de saúde se faz constante; e para que isto ocorra, a assistência deve estar ajustada com a vivência, os desejos e as necessidades das famílias, que devem ser pensadas como coparticipantes do cuidar e ser auxiliadas no cuidado à saúde e na promoção do bem-estar de seus membros. Esta deve ser uma assistência que permite às famílias não se sentirem sozinhas no enfrentamento de seus problemas, uma vez que o acúmulo destes pode resultar em doença nas suas mais diversificadas manifestações. 
Em relação à possibilidade de melhora do quadro, percebemos a necessidade incessante de buscar a cura pela família. Quando ela se encontra com a impossibilidade de cura, observamos o descontentamento e o desânimo, principalmente dos que cuidam diariamente. Nestes casos, o profissional de saúde mental se depara com expectativas pessimistas dos familiares, principalmente pelo fato de não acreditarem na transformação de uma realidade que permaneceu inalterada durante muito tempo. A busca pela cura do transtorno mental passou por transformações ao longo da história - por exemplo, enquanto antes dos ideais de desinstitucionalização havia a busca incessante pela cura, hoje a ênfase não é mais colocada neste processo, mas no processo de invenção da saúde e de reprodução social do presente ${ }^{(16)}$. Isto pode ser evidenciado por meio do relato da próxima depoente.

Nossa, menina! Tinha vez que eu falava que ia desanimar, falava "eu não vou atrás mais de consulta, eu não vou atrás de nada, de internamento, não vou mais". E eu começava a chorar, eu pegava, saía de dentro de casa e ia parar lá debaixo das árvores e lá começava a chorar. Menina do céu! Eu ficava nervosa, eu chorava escondido assim, para eles não verem que eu estava chorando. Eu queria me controlar, sabe, mas eu não conseguia. Eu vivia assim, escondida, chorando, de ver ele naquela situação, que ele estava... pior do que criança! Ficou bem pior! (Coruja)

Na linguagem de Coruja, notamos que a vivência com a esquizofrenia em seu lar suscita-lhe o desejo de fugir do mundo. Vislumbramos em suas palavras um ser que, enredado em sua missão, afunda-se na desesperança. Diante da manifestação da depoente, entendemos que, muitas vezes, o cuidador sente-se limitado para cuidar de seu ente familiar com transtorno mental e encontra dificuldade de se reunir, discutir e resolver seus problemas no seio familiar, isolando-se do convívio de outras pessoas para ocultar sua dor ${ }^{(1)}$.

Diante destas palavras, acreditamos que 0 profissional enfermeiro deve levar em conta as singularidades de cada família, avaliando suas necessidades específicas e as ações da enfermagem a serem desenvolvidas, com vista a prevenir futuros episódios e manter a qualidade de vida do grupo familiar.

Estudo ${ }^{(17)}$ expõe que desde a formação é preciso proporcionar ao acadêmico a vivência interdisciplinar em que não haja hierarquia e nem busca de poder, mas um encontro em que se busca a saúde integral das pessoas, principalmente aquelas que são acometidas pelo transtorno mental, buscando melhorar suas condições de vida. Deve-se buscar um trabalho em conjunto, vislumbrando o atendimento à família com vistas à transformação da realidade exigindo conhecimento de conceitos de saúde mental, de família, estrutura familiar, função familiar, entre outros ${ }^{(17)}$.

Também encontramos na literatura que o cuidado como prática social fornece substratos para o desenvolvimento social, ou seja, a percepção de ampliação de espaços e oportunidades para aperfeiçoamento de potencialidades constitui-se, para o enfermeiro, em importante instrumento de inclusão social(18). O depoimento abaixo faz refletir sobre a singularidade de cada familiar, a visão particularizada do transtorno mental e a forma de enfrentá-lo.

Teve época de eu pedir, de gritar alto: "Meu Deus, o Senhor esqueceu de mim, não é possível! Não é possivel tanta coisa só para mim!". E sabe assim, você ficar no meio louquinha.. assim, sem saber o que fazer? Teve dia de gritar com Deus: "Meu Deus, o Senhor esqueceu de mim! Eu acho que nem existe Deus". Até isso eu falava! [...] Já está avançado de um jeito assim que a gente se acaba, a gente se estressa, sabe, que a gente vai indo que não aguenta mais, e nós estamos nessa ainda, sabe? Porque tudo o que a gente fez... nossa! Eu disse para ele: "Eu já dei a vida, meu filho, para te salvar e você não quis. Só que hoje eu não dou mais, eu não vou me matar por você". Eu cansei, eu cansei. Eu falei: "Eu já tô velha, tá na hora de eu descansar, vocês não deixam eu descansar, eu tenho pouco tempo de vida para mim viver e vocês têm tudo pela frente. Se vocês não querem então deixa a gente viver. Vá fazer o que você quiser da vida. Porque eu cansei". Quando veio para casa, na primeira esquina ele foi beber. Valeu a pena eu perder todo aquele tempo ali com o braço enfaixado? Então, é onde que a família cansa, chega uma época assim que a gente diz: "chega, eu não quero mais e pronto!" (Mandarim) 
Nas palavras de Mandarim, distinguimos que o desânimo e o dispêndio do tempo para o cuidado são fatores que permeiam o seu cotidiano de forma a levá-la a acreditar que nada adianta cuidar, uma vez que não visualiza a possibilidade de recuperação de seu familiar.

Diante disto, no trabalho com famílias, em qualquer abrangência e área específica de intervenção, é preciso levar em conta o contexto dinâmico e singular de seu cotidiano. É necessário, ainda, considerá-la como um território de ambiguidade nas relações, ou seja, há um misto de sentimentos que passam a desenvolver-se em situação oposta, como, por exemplo, amor e ódio, esperança e desesperança, companhia e solidão. Estes sentimentos foram evidenciados por profissionais que trabalham com famílias de pessoas com transtorno mental no domicílio, quando se verificou que as mesmas sentem-se sobrecarregadas com o cuidado de seu familiar doente; por isso o profissional precisa oferecer um cuidado adequado às suas necessidades, e este cuidado precisa pautar-se em suas potencialidades, o que não pode significar a desobrigação do serviço de saúde e do Estado(11).

A desesperança também assume ainda a conotação de desespero e sofrimento a que o familiar atribui um único sentido: a morte. A morte seria a etapa final para a extirpação dos sentimentos de impotência diante do enfrentamento da doença. O cuidado, para esta familiar, não existe como possibilidade de ser compartilhado com outras pessoas, e isto lhe causa muito sofrimento.

Ele desestrutura tua cabeça, teu corpo, teu coração, tua mente. Chega um dia que você quer morrer. Eu cheguei a pedir para Deus para eu morrer e ele também, porque eu queria ir, mas eu queria levar ele junto, não queria deixar ele, porque ninguém aqui na terra ia ter a paciência que eu tenho com ele, ninguém, eu sei que ninguém, a não ser eu e Deus. Até que eu não conhecia o verdadeiro amor de Jesus eu não podia falar, eu chorava. Eu tremia, chorava, rodava tipo... um filme na minha cabeça. Mas eu chorei muito por ele. Eu não podia ver ele do jeito que ele chegava, eu chorava. Às vezes eu ia dormir, perdia o sono, eu começava chorar, não sabia como é que ia ser o outro dia. Eu era assim, uma pessoa que chorava muito fácil. Todo o sofrimento dele atingia a mim. (Águia)

Na fala, Águia traz a desesperança arraigada em seu cotidiano. Desta forma, observa-se a importância do enfermeiro em orientar estas famílias quanto à tarefa de cuidar. As orientações podem contribuir significativamente para que estas famílias recuperem a esperança e para que não desistam do tratamento.

As dificuldades impostas ao cuidador familiar da pessoa esquizofrênica são inúmeras, pois é preciso acolher estes familiares nos serviços de saúde mental, conhecer as condições de sua sobrecarga e de suas necessidades, de modo a tornar mais efetivas as intervenções junto às famílias ${ }^{(5)}$.

Eu falava "eu vou morrer logo, eu não aguento mais essa vida", porque eu vi que ele não queria tomar os remédios, não se endireitava e, nossa! A minha vida era chorar, menina do céu! Até um dia eu falei pro médico, falei: "Eu acho que logo sou eu quem tem que estar se tratando aqui também". (Coruja)

A sobrecarga em famílias de pessoas com transtorno mental se apresenta de duas formas ${ }^{(19)}$, a sobrecarga objetiva se relaciona aos problemas ou dificuldades físicas provocadas pelos comportamentos do paciente. A subjetiva se refere aos sentimentos pessoais sobre o ato de cuidar e está relacionada às conseqüências da sobrecarga objetiva. Assim, observamos que a sobrecarga subjetiva, se adapta à fala de Coruja que é referente aos sentimentos, aquilo que não se mede, algo que acomete a alma, que dói, que a faz sofrer pelas condições de ser cuidador. Desta forma, é possível inferir que o momento de crise do familiar foi também aquele que the acarretou a maior sobrecarga. Essas palavras nos levam a pensar na necessidade de implementar medidas preventivas urgentes, pois a ansiedade, depois de instalada, é muito difícil de ser eliminada. A nosso ver, o sustentáculo para sobrepujar essas situações poderá ser buscado junto ao serviço de saúde, em diferentes momentos, com objetivo de aliviar a sobrecarga, criando e fortalecendo o vínculo entre o serviço e a família(4).

\section{CONSIDERAÇÕES FINAIS}

Depreende-se deste estudo que a convivência com a pessoa esquizofrênica é permeada por diversos sentimentos, como pesar, preconceito e desesperança. Desta forma, o familiar se vê envolto em sentimentos muitas vezes incompreendidos por ele mesmo, sentindose sobrecarregado com os cuidados diários ao seu 
familiar com transtorno mental, chegando a preferir a morte à experiência de lidar com a "loucura".

É fato que o despreparo destas famílias leva o cuidador a assumir um espectro de padecimento; porém um desafio que ainda permeia o cuidado a estas famílias se refere à tarefa do enfermeiro de fazer valer o direito à informação, promover o acesso destas famílias a mecanismos que as orientem a exercer da melhor forma este cuidado e, principalmente, a trabalhar com estas famílias para atender às suas demandas secundárias. A saúde é um todo, e quando é atingida uma parte da família, o seu todo acaba sofrendo as consequências.

Para estes familiares, ter um portador de esquizofrenia no lar transcendeu, em muito, os aspectos físicos e espirituais aqui relatados. Compartilhar sua vivência com a enfermeira remeteu a um desabafo que foi entendido como nunca experienciado por um profissional de saúde, pois muitas vezes o foco estava voltado ao indivíduo esquizofrênico, e não à família, que é onde os entraves e as dificuldades se manifestam.
Experienciar junto a estas famílias suas vivências quanto ao cuidado fez-me perceber quão tênue é a linha entre o amor e o ódio, a razão e a emoção, a esperança e a desesperança. Nessa situação, o apoio da equipe de saúde é de suma importância, não só para que o cuidador possa trabalhar no sentido de diminuir o número de internações de seu familiar, mas principalmente para que, provido de condições, este cuidador seja capaz de criar mecanismos que sustentem sua prática. Caso o cuidador não vislumbre a importância de seu papel no cuidado, provavelmente a percepção do cuidado que está sendo oferecido também está alterada. É possível cuidar melhor quando o cuidador percebe preocupação e ações de cuidado da Enfermagem voltadas a ele mesmo.

Desta forma, recomenda-se a ampliação da atenção à família no que refere às suas necessidades de cuidado, para que juntos, portador de esquizofrenia, familiar e equipe de saúde, possam vislumbrar com esperança caminhos para uma assistência integral.

11. Waidman MAP, Radovanovic CAT, Scardoelli, MGC, Estevan MC, Pini JS, Brischiliari A. Estratégia de cuidado a famílias de portadores de transtorno mentais: experiências de um grupo de pesquisa. Cienc Cuid Saude 2009; 8 (suplem.):97-103

12. Estevam MC, Marcon SS, Antonio MM, Munari DB, Waidman MAP. Convivendo com transtorno mental: perspectiva de familiares sobre atenção básica. Rev Esc Enferm USP 2011; 45(3):679-86 13. Alves CFO, Ribas VB, Alves EUR, Viana MI, Ribas RMG, Melo Junior RP, et al.Uma breve história da reforma psiquiátrica. Neurobiologia, 2009;72(1):85-96.

14. Halbwachs M. A Expressão das emoções e a sociedade. Tradução de Mauro Guilherme Pinheiro Koury. RBSE [internet] 2009 [cited 2009 jul 01];8(22):201-18. Available from:

http://www.cchla.ufpb.br/rbse/HalbwachsTrad.pdf

15. Barroso SM, Bndeira M, Nascimento E. Fatores preditores da sobrecarga subjetiva de familiares de pacientes psiquiátricos atendidos na rede pública de Belo Horizonte, Minas Gerais, Brasil. Cad. Saúde Pública. 2009;25(9):1957-68.

16. Millani HFB, Valente MLLC. O caminho da loucura e a transformação da assistência aos portadores de sofrimento mental. SMAD, Rev. Eletrônica Saúde Mental Álcool Drog [Internet]. 2008 [cited 2011 mar 29]; 4(2): 1-19. Available from:

http://pepsic.bvsalud.org/pdf/smad/v4n2/v4n2a09.pdf. 17. Silva KVLG, Monteiro ARMA família em saúde mental: subsídios para o cuidado clínico de enfermagem. Rev Esc Enferm USP 2011;45(5):1237-42.

18. Backes DS, Backes MS, Erdmann AL. Promovendo a cidadania por meio do cuidado de enfermagem. Rev Bras Enferm. 2009;62(3):4304.

19. Soares CB, Munari DB. Sobrecarga em familiares de pessoas com transtorno mental Cienc Cuid Saude 2007;6(3):357-362.

Artigo recebido em 19.04.2011.

Aprovado para publicação em 13.03.2012.

Artigo publicado em 30.03.2012. 